Article

\title{
Molecular Properties of Water-Unextractable Proteoglycans from Hypsizygus marmoreus and Their in Vitro Immunomodulatory Activities
}

\author{
Hong Hui Bao ${ }^{1, \dagger}$, Mehdi Tarbasa ${ }^{1}$, Hee Mun Chae ${ }^{2, *}$ and Sang Guan You ${ }^{1, *}$
}

1 Department of Marine Food Science and Technology, Gangneung-Wonju National University, 120 Gangneung Daehangno, Gangneung, Gangwon, 210-702, Korea

E-Mails: honghui_bao@163.com (H.H.B.); mtabarsa@yahoo.com (M.T.)

2 Climate Change Research Institute of Korea, Chuncheon-si, Gangwon-do, 200-939, Korea

$\dagger$ Present address: College of Food Science, Heilongjiang Bayi Agricultural University, Heilongjiang, Daqing 163319, China.

* Authors to whom correspondence should be addressed; E-Mails: cheemun6606@hotmail.com (H.M.C.); umyousg@gwnu.ac.kr (S.G.Y.); Tel.: +82-33-254-2103 (H.M.C.); +82-33-640-2853 (S.G.Y.); Fax: +82-33-254-2014 (H.M.C.); +82-33-640-2340 (S.G.Y.).

Received: 27 October 2011; in revised form: 7 December 2011 / Accepted: 22 December 2011 / Published: 27 December 2011

\begin{abstract}
Four proteoglycans were sequentially extracted from Hypsizygus marmoreus using $0.1 \mathrm{M} \mathrm{NaOH}$ (alkali-soluble proteoglycans [F1] and alkali-insoluble proteoglycans [F3]) and $0.1 \mathrm{M} \mathrm{HCl}$ (acid-soluble proteoglycans [F2] and acid-insoluble proteoglycans [F4]), and their structures and immunomodulatory activities were investigated. The proteoglycans were found to contain carbohydrates (19.8-82.4\%) with various amounts of proteins (7.7-67.3\%), and glucose was the major monosaccharide unit present, along with trace amounts of galactose. The molecular weights $(\mathrm{Mw})$ and the radius of gyration $(\mathrm{Rg})$ of these proteoglycans showed ranges of $16 \times 10^{4}-19,545 \times 10^{4} \mathrm{~g} / \mathrm{mol}$ and $35-148 \mathrm{~nm}$, respectively, showing significant variations in their molecular conformations. The backbones of $F 1$ and F2 were mainly connected through $\alpha-(1 \rightarrow 3),(1 \rightarrow 4)$ and $\beta-(1 \rightarrow 6)$-glycosidic linkages with some branches. The F1 and F2 proteoglycans significantly stimulated Raw264.7 cells to release nitric oxide (NO), prostaglandin E2 $\left(\mathrm{PGE}_{2}\right)$ and various cytokines, such as IL-1 $\beta$, TNF- $\alpha$ and IL- 6 by inducing their mRNA expressions.
\end{abstract}


Keywords: Hypsizygus marmoreus; proteoglycan; immunomodulation activity; molecular conformation; glycosidic linkages

\section{Introduction}

Edible mushrooms have been widely used for millennia as a food delicacy, a source of important medicinal substances and as nutritional supplements. Among the various constituents, such as essential amino acids, proteins, carbohydrates, minerals and vitamins; polysaccharides have attracted considerable attention from biochemical and nutritional researchers because of their potential importance as functional foods and medicinal ingredients. Polysaccharides from Lentinus edodes, Schizophyllum commune and Coriolus versicolor are well known to have strong antitumor activity and are commercially available as anticancer supplements [1-3]. It has been reported that the soluble polysaccharides from Tricholoma sp. improved the proliferation of peritoneal macrophages in mice and inhibited tumor cell growth, possibly through the enhancement of the host immune system [4]. In contrast, the polysaccharides from Pleurotus ostreatus and Pleurotus tuber-regium directly suppressed the growth of cancer cell lines (HT-29 and HL-60) by upregulating the pro-apoptotic molecules, Bax and cytosolic cytochrome-c [5,6].

It is well known that the antitumor and immunomodulatory activities of the polysaccharides are closely related with their primary and secondary structures [7]. According to Demleitner et al. [8], the $\beta$ - $(1 \rightarrow 3)$-glycosidic linkage was proposed to be essential for antitumor activity in the study of curdlan and licheman derivatives. However, there are various antitumor polysaccharides from mushrooms having other glycosidic linkages, such as $\alpha$-(1 $\rightarrow 4)$-glycoside [9], $\beta-(1 \rightarrow 6)$-glycoside, $\alpha-(1 \rightarrow 6)$-heteroglycoside [10]. Maeda and Watanabe [11] mentioned the importance of secondary structures of the polysaccharides, reporting that the triple helical conformation led to higher stimulation of the T-cell mediated immune responses than did single chains of $\beta$-D-glucan. The molecular weight of mushroom polysaccharides has also been suggested to be an important factor to its bioactivities, reporting that high molecular weight glucans ranging from 500-2,000 kDa were more effective than those of lower molecular weight [12]. Although there is much controversy surrounding the relationship between molecular structures and biological activities, it is still important to characterize the primary and higher-order structures of polysaccharides and to correlate the structures with those bioactivities.

Hot water-extraction has been a popular approach for extracting polysaccharides from fungal cell walls, but it should be noted that considerable quantities of water-unextractable polysaccharides with various structures and bioactivities were also found $[13,14]$. In our previous work, we showed that water-soluble polysaccharides from Hypsizygus marmoreus exhibited strong immunomodulation, possibly with antitumor activity. However, the structural characteristics and biological activities of the water-unextractable polysaccharides from $H$. marmoreus are currently not known. Therefore, in this study, water-unextractable proteoglycans were sequentially extracted, from the residue after water-extraction of $H$. marmoreus, using dilute alkali and acid. The purpose of this study was to investigate the structural characteristics of the water-unextractable proteoglycans from $H$. marmoreus and to investigate their immunomodulatory activities. 


\section{Results and Discussion}

\subsection{Chemical Composition Analysis}

When the yield and chemical composition of water-unextractable proteoglycans (F1, F2, F3 and F4) were investigated, the largest amount was observed in the F1 fraction (7.5\%) collected from the water-insoluble residue, while relatively small amounts of F3 and F4 fractions ( 0.3 and $0.4 \%)$ were obtained. The water-insoluble residue also contained a substantial amount of the F2 fraction (1.9\%). The total yield $(10.1 \%)$ of water-unextractable proteoglycans was a little lower than that of water-extractable proteoglycans $(12 \%)$, as reported in our previous study [15]. The lower yield of the water-unextractable proteoglycans was probably due to the use of dilute alkali and acid $(0.1 \mathrm{~N})$ for the extraction of the proteoglycans to prevent their molecular degradation. Similar results were observed in a report by Hromadkova et al. [16]; in which, the total yield of water-unextractable polysaccharides from Salvia officinalis was significantly lower than that of the water-extractable polysaccharides.

The constituents of F1 and F2 were mainly carbohydrates (62.8\% and $82.4 \%$, respectively) containing considerable amounts of proteins (16.5\% and 7.7\%, respectively). The proteins were retained in F1 and F2 fractions after repeated Sevag treatments, suggesting that the proteins in F1 and F2 might be covalently bound to the polysaccharides. When compared with the carbohydrate $(55.8 \%)$ and protein (23.0\%) contents of the water-extractable polysaccharides reported in our previous study [15], the water-unextractable proteoglycans contained higher quantities of carbohydrates and lower quantities of proteins. However, significant amount of proteins $(39.7 \%$ and $67.3 \%$, respectively) were included in alkali and acid insoluble (F3 and F4) fractions. This suggested that the solubility of the water-unextractable proteoglycans might be related to protein content. It is likely that the proteins in F3 and F4 were initially soluble at alkaline conditions but became insoluble when the $\mathrm{pH}$ of solution became neutral, possibly because of their intra and/or inter-molecular interactions. This $\mathrm{pH}$ change seemed to cause the aggregation of F3 and F4, followed by their precipitation. Similar results were also observed in the study of proteoglycans, which were initially soluble in $0.04 \mathrm{M} \mathrm{NaOH}$ but became insoluble at neutral $\mathrm{pH}$ due to the intra and/or inter-molecular interactions of proteins [17].

Monosaccharide composition analysis revealed that glucose was the major sugar in the water-unextractable proteoglycans and a considerable amount of galactose $(8 \%)$ was only found in the F4 fraction. As reported in our previous study [15], glucose was also a major sugar in the water-extractable polysaccharides with slightly higher quantities of galactose $(11.6 \%)$, which implied that the polysaccharides of the fruiting body from $H$. marmoreus were relatively homogeneous polysaccharides mainly consisting of glucose as a major monomer unit. Other monosaccharides such as mannose, xylose and fucose were not detected in the current study.

\subsection{Molecular Characteristics of Proteoglycans}

The UV and RI superimposed chromatograms for the water-unextractable proteoglycans are shown in Figure 1. F1 and F2 were eluted from the SEC column between the elution times of 24.2 and $52.1 \mathrm{~min}$ having major, distinct peak areas at 50.5 and 36.2 min, respectively, with some minor peaks, which indicated that both proteoglycans had heterogeneous polymer distributions (Figures 1a,b). The ratios of the peaks were significantly different between F1 and F2. Similar distribution ratios of high and low 
molecular weight fractions were observed for F1 while most polysaccharides were included in higher molecular weight fractions for F2. The UV chromatogram indicated that proteins were mostly included in peak II between the elution times of 44.2 to $52.1 \mathrm{~min}$. Table 1 showed that the $\mathrm{M}_{\mathrm{w}}$ values of the peaks were $753 \times 10^{4} \mathrm{~g} / \mathrm{mol}$ and $16 \times 10^{4} \mathrm{~g} / \mathrm{mol}$ for F1 and $259 \times 10^{4}$ and $25 \times 10^{4} \mathrm{~g} / \mathrm{mol}$ for F2, respectively. This is the first report for the $\mathrm{M}_{\mathrm{w}}$ of the water-unextractable proteoglycans from $H$. marmoreus. In the study of water-unextractable polysaccharides from other mushrooms including P. tuber-regium, P. ostreatus, P. eryngii and Laetiporus sulphureus, the $\mathrm{M}_{\mathrm{w}}$ values ranged from $5.8 \times 10^{4} \mathrm{~g} / \mathrm{mol}$ to $290 \times 10^{4} \mathrm{~g} / \mathrm{mol}$, exhibiting significant variations [18-20]. These considerable variations in the $\mathrm{M}_{\mathrm{w}}$ might be attributable to differences, not only in the mushroom species but also in the extraction, purification and analysis methods as well as the different life cycles of the mushrooms. The radius of gyrations $\left(\mathrm{R}_{\mathrm{g}}\right)$ for $\mathrm{F} 1$ and $\mathrm{F} 2$ were also calculated from the peaks to estimate the approximate sizes of the proteoglycans (Table 1). The $R_{g}$ values of the two peaks of F1 and F2 were 73 and $136 \mathrm{~nm}$, and 50 and $148 \mathrm{~nm}$, respectively. Although peak II had significantly lower $\mathrm{M}_{\mathrm{w}}$, their $\mathrm{R}_{\mathrm{g}}$ values were greater than those of peak I. This was probably due to differences in the molecular conformation of the proteoglycans, suggesting that the polysaccharides of peak II might exist in an extended conformation while those of peak I in a more compact conformation, possibly through the intra-molecular interactions. The molecular conformation was also assumed by the specific volume for gyration $\left(\mathrm{SV}_{\mathrm{g}}\right)$ calculated by the values of $\mathrm{M}_{\mathrm{w}}$ and $\mathrm{R}_{\mathrm{g}}$, as reported by You and Lim [21] based on the following equation:

$$
\mathrm{SV}_{\mathrm{g}}=4 / 3 \pi\left(\mathrm{R}_{\mathrm{g}} \times 10^{8}\right)^{3} /\left(\mathrm{M}_{\mathrm{w}} / \mathrm{N}\right)=2.522 \mathrm{R}_{\mathrm{g}}^{3} / \mathrm{M}_{\mathrm{w}}
$$

Figure 1. RI and UV chromatograms of the water-unextractable proteoglycans (a) F1, (b) F2, (c) F3 and (d) F4 from H. marmoreus.

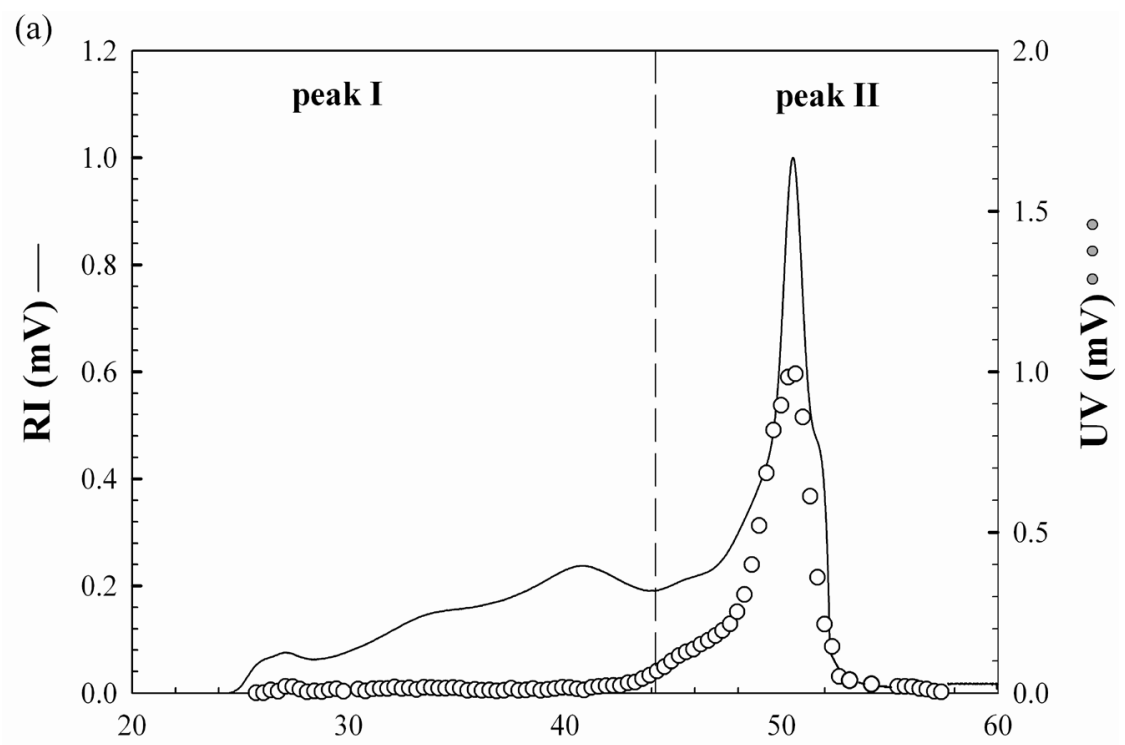

Elution time (min) 
Figure 1. Cont.

(b)

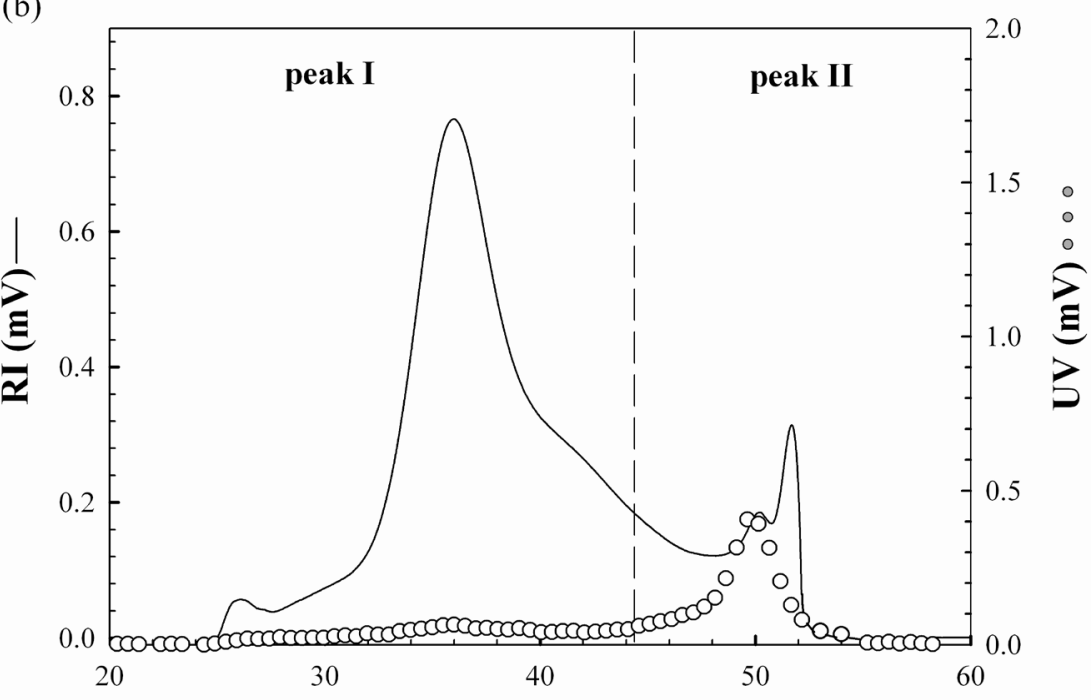

Elution time (min)

(c)
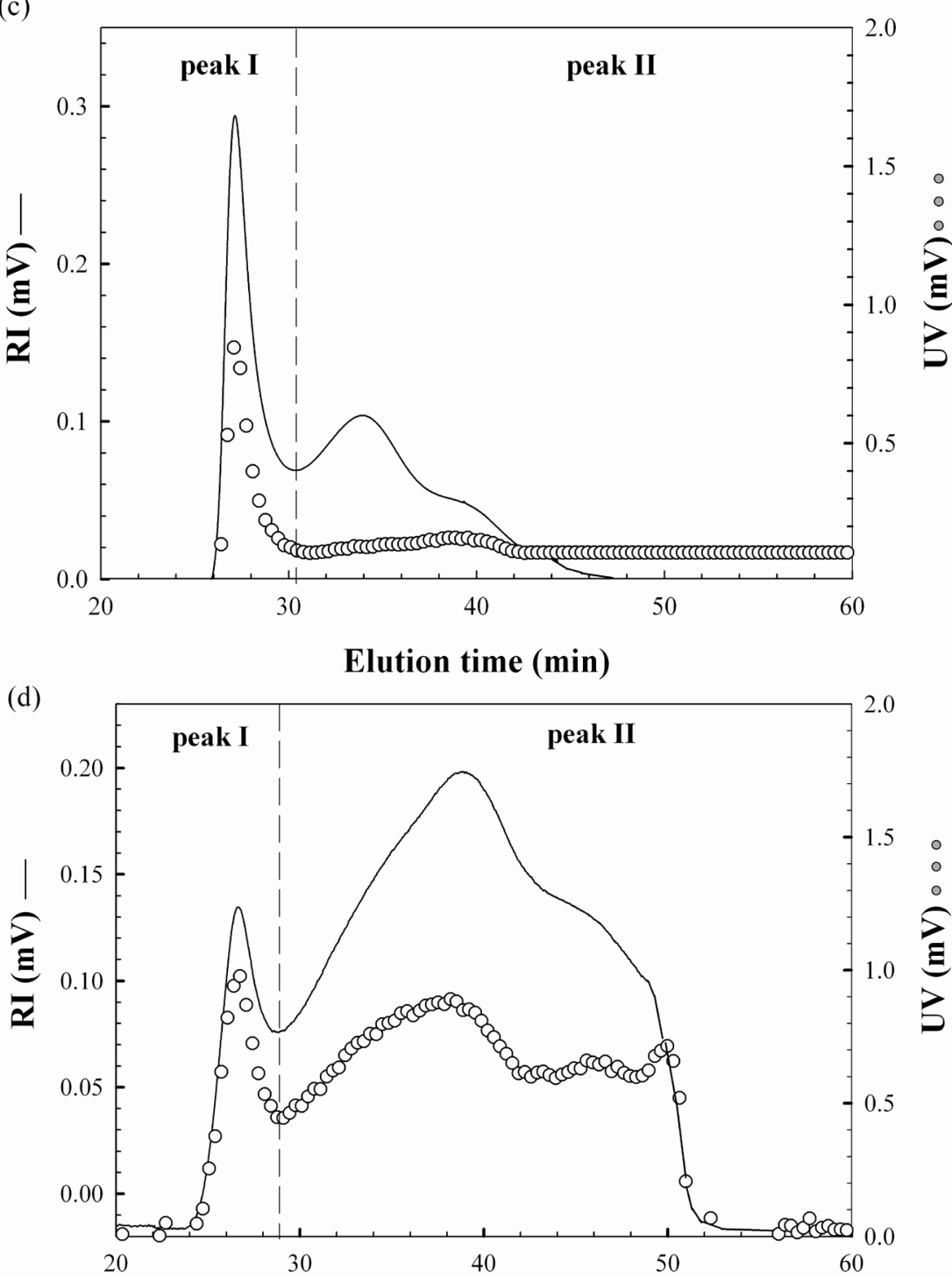

Elution time (min) 
Table 1. Weight average molecular weights $\left(\mathrm{M}_{\mathrm{w}}\right)$, radius of gyration $\left(\mathrm{R}_{\mathrm{g}}\right)$ and specific volume for gyration $\left(\mathrm{SV}_{\mathrm{g}}\right)$ of proteoglycans $(\mathrm{F} 1, \mathrm{~F} 2, \mathrm{~F} 3$ and $\mathrm{F} 4)$ extracted from H. marmoreus.

\begin{tabular}{ccccccccc}
\hline \multirow{2}{*}{ Sample } & \multicolumn{2}{c}{ Ratio (\%) } & \multicolumn{2}{c}{$\mathbf{M}_{\mathbf{w}} \times \mathbf{1 0}^{\mathbf{4}} \mathbf{( g / \mathbf { m o l } )}$} & \multicolumn{2}{c}{$\left.\mathbf{R}_{\mathbf{g}} \mathbf{( n m}\right)$} & \multicolumn{2}{c}{$\mathbf{S V}_{\mathbf{g}}\left(\mathbf{c m}^{\mathbf{3}} / \mathbf{g}\right)$} \\
\cline { 2 - 8 } & Peak I & Peak II & Peak I & Peak II & Peak I & Peak II & Peak I & Peak II \\
\hline F1 & 48.0 & 52.0 & $753 \pm 8$ & $16 \pm 1$ & $73 \pm 1$ & $136 \pm 1$ & $0.133 \pm 0.005$ & $40.5 \pm 2.06$ \\
F2 & 82.0 & 18.0 & $259 \pm 4$ & $25 \pm 1$ & $50 \pm 1$ & $148 \pm 6$ & $0.124 \pm 0.008$ & $32.8 \pm 1.66$ \\
F3 & 41.1 & 58.9 & $8428 \pm 48$ & $1797 \pm 18$ & $37 \pm 0$ & $35 \pm 1$ & $0.002 \pm 0.000$ & $0.006 \pm 0.000$ \\
F4 & 10.0 & 90.0 & $19,545 \pm 98$ & $444 \pm 5$ & $123 \pm 6$ & $40 \pm 2$ & $0.024 \pm 0.001$ & $0.037 \pm 0.001$ \\
\hline
\end{tabular}
nd: not detected.

The units for $\mathrm{SV}_{\mathrm{g}}, \mathrm{M}_{\mathrm{w}}$ and $\mathrm{R}_{\mathrm{g}}$ were $\mathrm{cm}^{3} / \mathrm{g}, \mathrm{g} / \mathrm{mol}$ and $\mathrm{nm}$, respectively. In the equation, $\mathrm{N}$ is Avogadro's number $\left(6.02 \times 10^{23} / \mathrm{mol}\right)$. The $\mathrm{SV}_{\mathrm{g}}$ value is inversely proportional to the degree of molecular compactness, providing the theoretical gyration volume per unit of molar mass, which gives the mass-based molecular density of proteoglycans. It was shown in Table 1 that the $\mathrm{SV}_{\mathrm{g}}$ values of the two peaks were 0.133 and 40.5 for F1 and 0.124 and 32.8 for F2, suggesting that the proteoglycans in peak II had less compact and more expanded conformational structures than those in peak I. This was also implied in the plot of $\mathrm{M}_{\mathrm{w}}$ and $\mathrm{R}_{\mathrm{g}}$ from Figure $2 \mathrm{a}$ that showed the polysaccharides from peak I of F1 and F2 had a relatively compact sphere conformation $(\alpha=0.31$ and $\alpha=0.33)$, while those from peak II were in the conformation of a random coil $(\alpha=0.42$ and $\alpha=0.41)$.

Figure 2. The plot of weight average molecular weight $\left(\mathrm{M}_{\mathrm{w}}\right)$ vs radius of gyration $\left(\mathrm{R}_{\mathrm{g}}\right)$ of proteoglycans: F1, F2, F3, and F4.

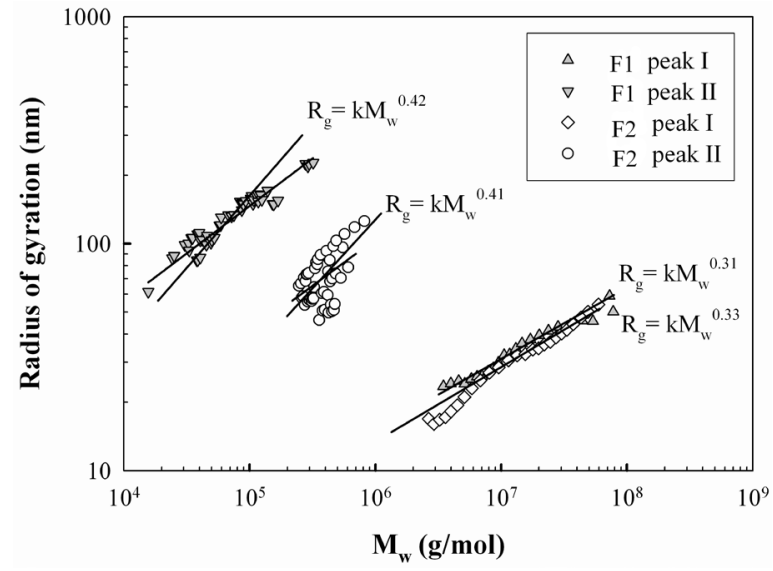

(a)

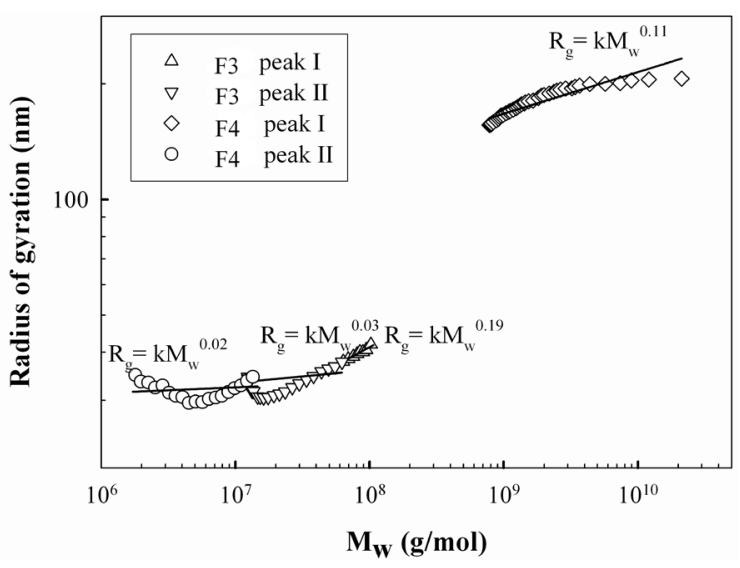

(b)

The RI and UV chromatograms of F1 and F2 are shown in Figures 1c,d. Two major peaks were observed, but their elution profiles were different from those of F1 and F2, showing distinct high molecular weight fraction peaks. Similar distribution ratios of high and low molecular weight fractions were also observed in F3, but most polysaccharides in F4 were eluted in peak II. The UV chromatograms indicated that proteins of F3 were mainly included in peak I between the elution times of 26 to 30 min, while those of F4 were contained in both peaks. This is considerably different from the F1 and F2 results, in which most proteins were eluted at peak II. The $M_{w}$ values of the peaks were $8,428 \times 10^{4} \mathrm{~g} / \mathrm{mol}$ and $1,797 \times 10^{4} \mathrm{~g} / \mathrm{mol}$ for F3 and 19,545 $\times 10^{4} \mathrm{~g} / \mathrm{mol}$ and $444 \times 10^{4} \mathrm{~g} / \mathrm{mol}$ for F4, respectively (Table 1), indicating that their $\mathrm{M}_{\mathrm{w}}$ values were significantly greater than those of $\mathrm{F} 1$ and F2, except in peak II of 
F4. The $\mathrm{R}_{\mathrm{g}}$ values of the two peaks of F3 and F4 were 37 and $35 \mathrm{~nm}$, and 123 and $40 \mathrm{~nm}$, respectively, with the ranges of $\mathrm{SV}_{\mathrm{g}}$ values from 0.002 to 0.037 , which indicated that the proteoglycans were in the more compact conformations than those of F1 and F2. This was also demonstrated in the plot of $\mathrm{M}_{\mathrm{w}}$ and $\mathrm{R}_{\mathrm{g}}$ (Figure $2 \mathrm{~b}$ ) that the polysaccharides of F3 and F4 had more compact sphere conformation ( $\alpha=0.03 \sim 0.19)$ than those of F1 and F2 ( $\alpha=0.31 \sim 0.41)$. It was not clear why the conformations of the proteoglycans between alkali/acid-soluble and alkali/acid-insoluble proteoglycans were considerably different. This is likely to be due to differences in protein content in these fractions because the ionic charges of the proteins seemed to be significant, leading to considerable intra-molecular interactions. Therefore, the amount of proteins included in the proteoglycan fractions would be an important factor contributing to proteoglycan conformation. Consequently, higher protein contents in F3 and F4 appeared to be enough to induce greater intra-molecular interactions of the polymers, resulting in more compact conformations. Furthermore, the presence of proteins at the high molecular weight fractions (peak I of Figures 1c,d), either bound or non-bound, might facilitate the molecular foldings of the high $\mathrm{M}_{\mathrm{w}}$ proteoglycans, which might also make a contribution on the molecular compactness of F3 and F4. Moreover, Bandtlow and Zimmermann [22] reported, that the molecular conformation of a proteoglycan, called glypican, might be influenced by the intra-molecular interactions of proteins conferring a rather compact shape on the proteoglycans.

\subsection{Immunomodulatory Activity of Water-Unextractable Proteoglycans}

A murine macrophage cell line, Raw264.7 cell, has been known to release cytokines in response to the addition of lipopolysaccharide, LPS, and this system has been used to determine the immunomodulating activities of compounds [23]. In the current study, the effect of water-unextractable proteoglycans on immunostimulation was determined using Raw264.7 cells by determining the released amount of NO, IL-1 $\beta$ and $\mathrm{PGE}_{2}$. The cytotoxic effect of the proteoglycans on the proliferation of Raw264.7 cells was evaluated at concentrations of $1.5-12 \mu \mathrm{g} / \mathrm{mL}$. It was shown that the proteoglycans did not considerably affect the proliferation of Raw264.7 cells, suggesting that the proteoglycans were not toxic to Raw264.7 cells over the concentration range tested in this study (data not shown). The NO production capacities of the water-unextractable proteoglycans at concentrations of $1.5-12 \mu \mathrm{g} / \mathrm{mL}$, expressed as the amount of NO released from Raw264.7 cells, are shown in Figure 3a. Lipopolysaccharide (LPS, $1 \mu \mathrm{g} / \mathrm{mL}$ ) was used as a positive control. It was shown that F1 significantly enhanced NO production $(14.8-21.0 \mu \mathrm{M})$ in a dose-dependent manner, comparable to the amount of NO produced by the positive control, LPS. This indicated that F1 could be a strong stimulant of Raw264.7 cells. The significant dose-dependent increase of NO release $(0.4-14.9 \mu \mathrm{M})$ was also shown in F2. On the other hand, the levels of NO production by F3 and F4 were found to be very low $(<2.7 \mu \mathrm{M})$, indicating a weak stimulatory activity on Raw264.7 cells. The release of NO from stimulated macrophages is an important molecule in the regulation of the immune system against tumors [24]. Therefore, the substantial increase in NO released from murine macrophages in the presence of F1 and F2 proteoglycans suggested that these proteoglycans could act as biological response modifiers in host defense mechanism and thus could improve the host immune response. It is not clear why F1 and F2 proteoglycans exhibited considerably higher NO releasing capacity than F3 and F4 proteoglycans. It has been reported that the immunomodulatory activities of polysaccharides are extensively dependent on their chemical composition, molecular weight, 
conformation, glycosidic linkage type and degree of branching, etc. [25]. Among the various factors reported, in the current study, it was likely that the different molecular conformation derived from various protein contents might be related with their immunostimulating capacity. F1 and F2 with more extended and loose conformations seemed to have better binding capacity on the cell surface receptors than F3 and F4 that had compact conformations that seemed to cause greater stimulation of Raw264.7 cells. This may be explained by the observation that in proteoglycans that adopt a compact conformation via intra-molecular interactions, the charged groups (mostly from proteins) available to bind the cell receptors may be buried inside the chains, and this causes a reduction in the binding capacity to the cell surface. On the other hand, if the proteoglycans were in the loose and entangled conformation, most charged groups existing in the chain are likely to be available to bind the cell surface, thus effectively enhancing the stimulation of the cells. In the study of polysaccharides having anionic sulfate groups, the molecular conformation was also suggested as a major factor that determined which polysaccharides inhibited the growth of cancer cells through its binding capacity on the receptor of the cell surface [26].

Figure 3. The effects of water-unextractable proteoglycans (F1, F2, F3 and F4) on (a) NO, (b) $\mathrm{PGE}_{2}$ and (c) IL-1 $\beta$ production. Cells were treated with the proteoglycans $(1.5,3,6$ and $12 \mu \mathrm{g} / \mathrm{mL})$ or LPS $(1 \mu \mathrm{g} / \mathrm{mL})$ for 24 h. ${ }^{\mathrm{x}, \mathrm{y}, \mathrm{z}}$ indicate a significant difference $(p<0.01)$ between the concentrations of the crude and individual fractions; ${ }^{a, b}, c, d$ indicate a significant difference $(p<0.01)$ between the crude and fractions at each concentration.

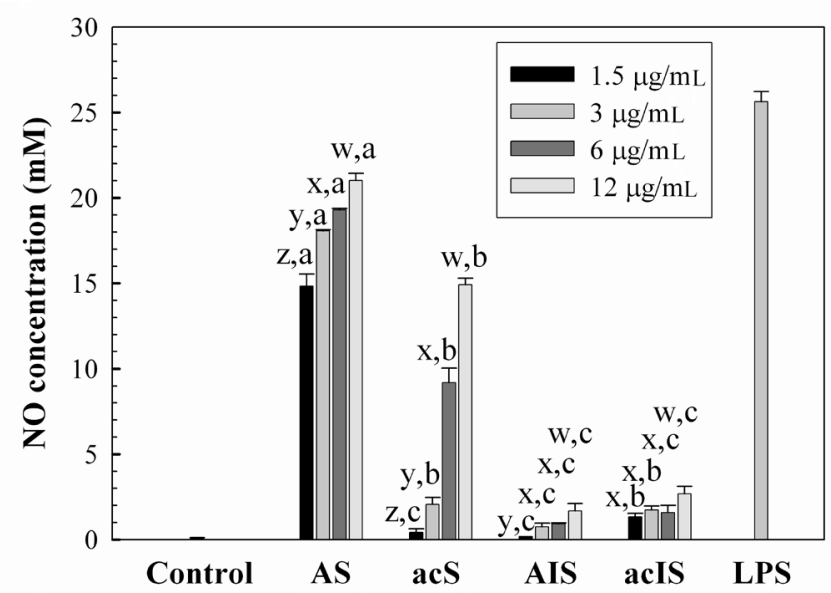

(a)

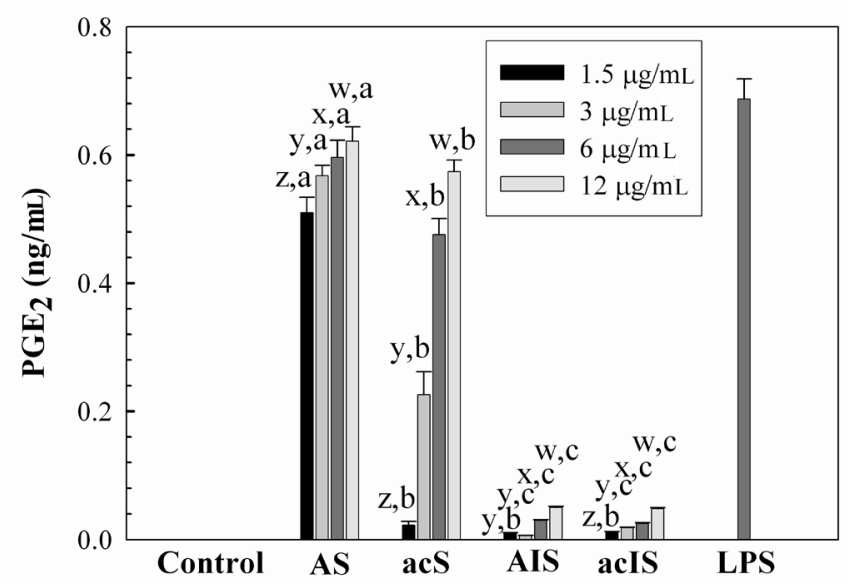

(b) 
Figure 3. Cont.

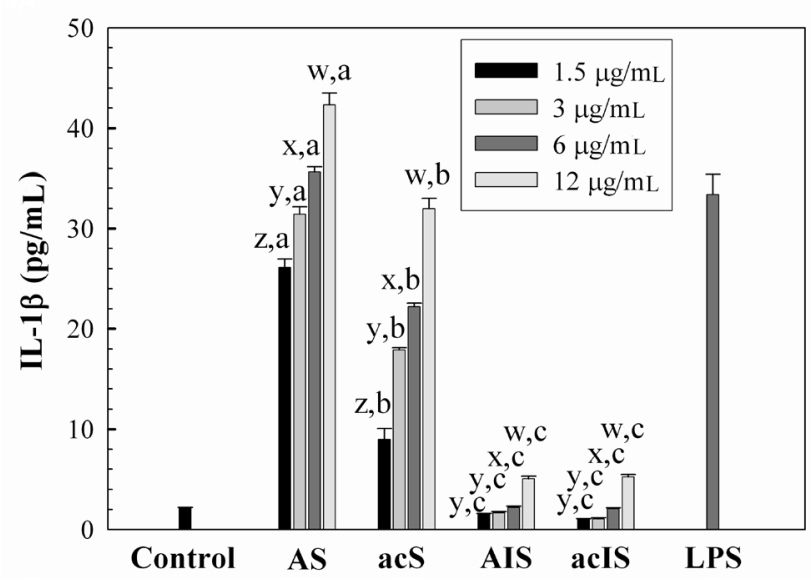

(c)

Similar trends were observed in the releases of $\mathrm{PGE}_{2}$ and IL-1 $\beta$ from Raw264.7 cells by the water-unextractable proteoglycans (Figures 3b,c). F1 and F2 exhibited considerably higher amounts of $\mathrm{PGE}_{2}(0.57-0.62 \mathrm{ng} / \mathrm{mL}$ at $12 \mu \mathrm{g} / \mathrm{mL})$ and IL-1 $\beta(32.0-42.0 \mathrm{pg} / \mathrm{mL}$ at $12 \mu \mathrm{g} / \mathrm{mL})$ production in a dosedependent manner than F3 and F4, which was comparable to the levels of $\mathrm{PGE}_{2}$ and IL-1 $\beta$ released by LPS.

We also evaluated whether the release of NO, PGE 2 and IL-1 $\beta$ from Raw264.7 cells as a result of the proteoglycans, might have an impact on mRNA expression of iNOS, COX-2 and IL-1 $\beta$ (Figures 4a-d). The mRNA expression patterns regulated by these proteoglycans at a concentration of $12 \mu \mathrm{g} / \mathrm{mL}$ were determined by agarose gel analysis of RT-PCR products with primers of iNOS, COX-2 and IL-1 $\beta$ mRNAs, and the levels of mRNA expression were obtained by the densitometric analysis. As shown in Figure 4, Raw264.7 cells treated with F1 and F2 produced more mRNAs than F3 and F4, which was in a good agreement with the results shown in Figure 3. Moreover, it was shown in Figures 4a,e,f that F1 and F2 also significantly induced mRNA expression of TNF- $\alpha$ and IL-6. It has been reported that activated macrophages can suppress tumor cell growth through the release of TNF- $\alpha$, which is responsible for killing cancer cells [27]. In addition, IL-6 has been regarded as a major immune mediator [28]. Therefore, the above results suggested that F1 and F2 might modulate host immune function by releasing various chemokines and/or cytokines, and thus could be potentially applied as a therapeutic agent for cancer treatment.

\subsection{Glycosidic Linkage Analysis of F1 and F2}

The polysaccharides of the most immuno-enhancing proteoglycans (F1 and F2) were permethylated according to Hakomori [29] followed by hydrolysis, reduction and acetylation of the partially methylated alditols to further investigate their structural characteristics, especially the glycosidic linkage types. Table 2 shows the types and ratios of glycosidic linkages of the polysaccharides determined by GC/MS. 
Figure 4. The effects of the water-unextractable proteoglycans (F1, F2, F3 and F4) on iNOS, COX-2, IL-1 $\beta$, TNF- $\alpha$ and IL-6 expression in Raw264.7 cells. (a) Representative PCR gels stained with ethidium bromide. Cells were incubated with LPS $(1 \mu \mathrm{g} / \mathrm{mL})$ and proteoglycans $(12 \mu \mathrm{g} / \mathrm{mL})$ for $18 \mathrm{~h}$. Total RNA was isolated, and mRNA expression was determined by RT-PCR; Graphic analysis of the PCR product for RNA levels of iNOS (b), COX-2 (c), IL-1 $\beta$ (d), TNF- $\alpha$ (e) and IL-6 (f). All data are presented as the mean \pm standard deviation $(\mathrm{n}=3)$.

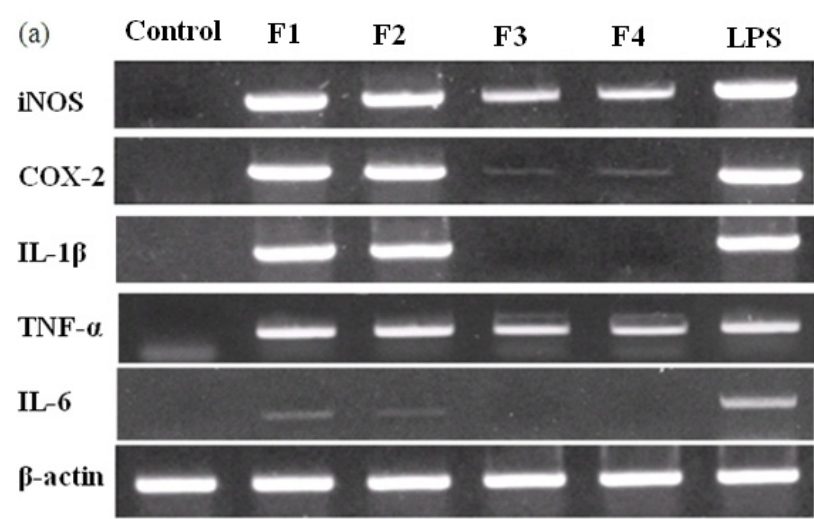

(c)

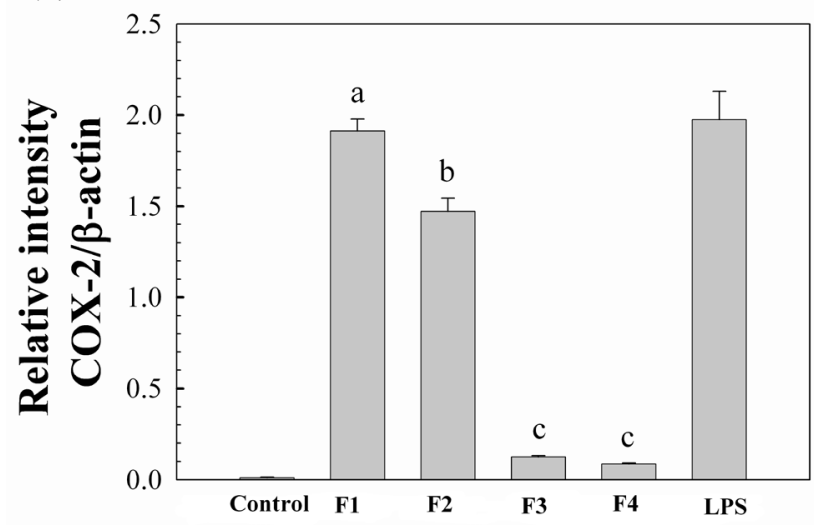

(e)

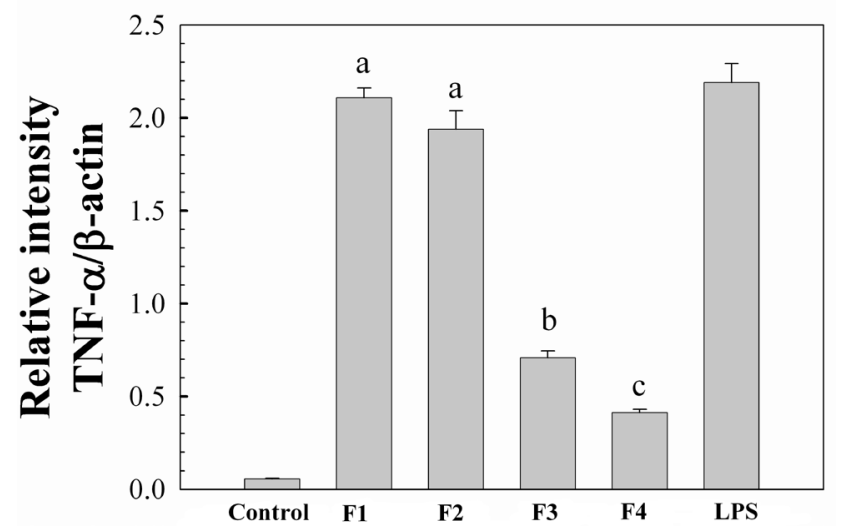

(b)

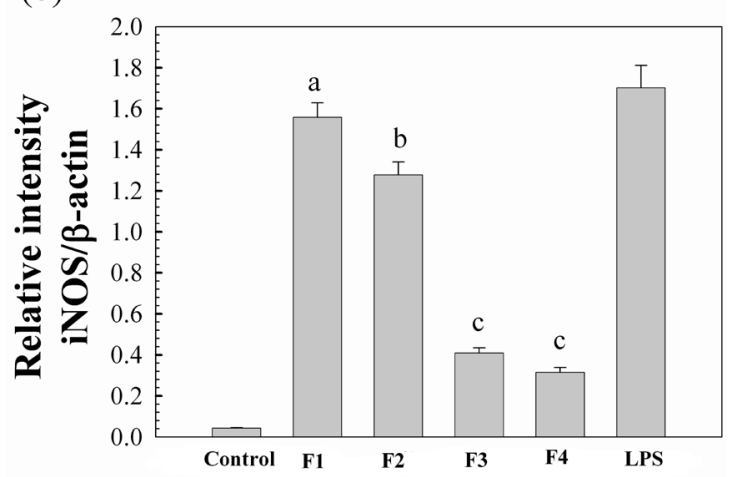

(d)

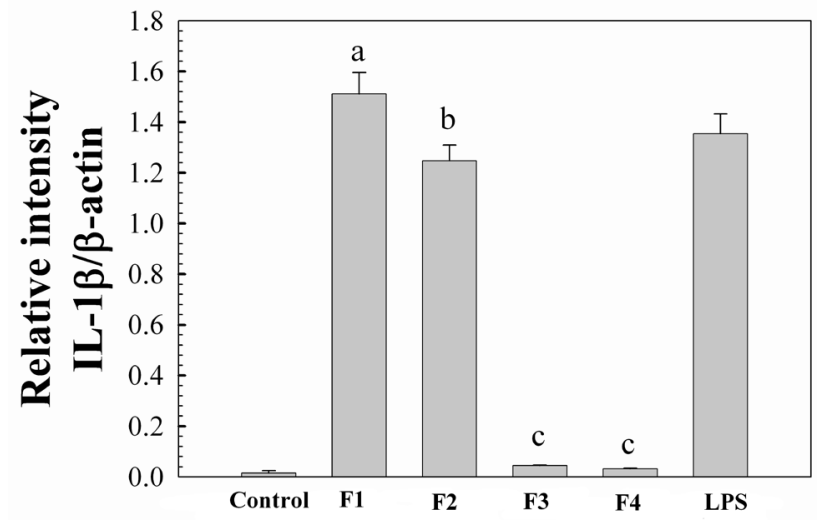

(f)

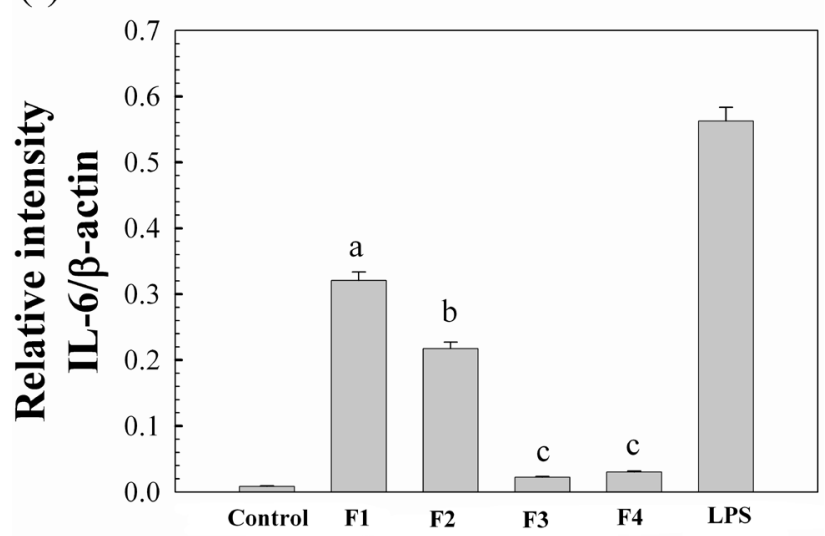


Table 2. Glycosidic linkage analysis of the constituent sugars of the F1 and F2 fractions originated from $H$. marmoreus.

\begin{tabular}{|c|c|c|c|c|c|}
\hline \multirow{2}{*}{$\begin{array}{c}\text { Methylated } \\
\text { sugars }^{\text {a }}\end{array}$} & \multirow{2}{*}{$\begin{array}{l}\text { Retention } \\
\text { time (min) }\end{array}$} & \multirow{2}{*}{ Mass fragmentation $(m / z)$} & \multirow{2}{*}{$\begin{array}{c}\text { Glycosidic } \\
\text { linkage }\end{array}$} & \multicolumn{2}{|c|}{ Peak area $(\%)$} \\
\hline & & & & F1 & F2 \\
\hline $2,3,4,6-\mathrm{Me}_{4}-\mathrm{Glc}$ & 9.64 & $43,59,71,87,102,118,129,145,162,174,205$ & Glc- $(1 \rightarrow$ & 12.9 & 21.2 \\
\hline 2,4,6- $\mathrm{Me}_{3}-\mathrm{Glc}$ & 11.29 & $43,59,71,87,101,118,129,161,234$ & $\rightarrow 3)$-Glc- $(1 \rightarrow$ & 8.7 & 29.0 \\
\hline 2,3,6- $\mathrm{Me}_{3}-\mathrm{Glc}$ & 11.47 & $43,59,71,87,102,118,129,142,162,173,233$ & $\rightarrow 4)$-Glc- $(1 \rightarrow$ & 57.0 & 19.1 \\
\hline 2,3,4-Me $-\mathrm{Glc}$ & 11.77 & $43,59,71,87,102,118,129,143,162,173,189,233$ & $\rightarrow 6)$-Glc- $(1 \rightarrow$ & 8.4 & 10.2 \\
\hline 2,3-Me $-\mathrm{Me}_{2}-\mathrm{Glc}$ & 13.44 & $43,59,74,85,102,118,127,142,162,201,261$ & $\rightarrow 4,6)$-Glc- $(1 \rightarrow$ & 6.2 & 2.9 \\
\hline $2,4-\mathrm{Me}_{2}-\mathrm{Glc}$ & 13.62 & $43,59,74,87,101,118,129,139,160,174,189,234$ & $\rightarrow 3,6)$-Glc- $(1 \rightarrow$ & 6.8 & 17.6 \\
\hline 2,3,4-Me $-\mathrm{Gal}$ & 12.26 & $43,59,71,87,102,118,129,142,162,173,189,233$ & $\rightarrow 6)$-Gal-( $(1 \rightarrow$ & nd & nd \\
\hline
\end{tabular}

It was shown that 2,3,6- $\mathrm{Me}_{3}$-Glcp was the most abundant component of the permethylated and acetylated derivatives from F1, which suggested that the backbones of the F1 polysaccharides might be mainly glucose molecules connected by 1,4-glycosidic linkages. In addition, F1 included small amounts of 2,4,6- $\mathrm{Me}_{3}$-Glcp and 2,3,4-Me $-\mathrm{Glcp}$, implying that the backbone was also connected through 1,3 or 1,6-glycosidic linkages. Furthermore, the presence of 1,4,6 or 1,3,6-linked glucose residues (2,3- $\mathrm{Me}_{2}-\mathrm{Glc}$ and 2,4-Me $\left.-\mathrm{Mlc}\right)$ indicated that some branches may exist along the backbone. The total percentage of terminal glucose was $12.9 \%$, which matched well with the branched portions (4,6- and 3,6-linked glucose: $13.0 \%$ ). The ratios of the glycosidic linkages of $1 \rightarrow, 1 \rightarrow 4,1 \rightarrow 3,1 \rightarrow 6$, $1 \rightarrow 4,6,1 \rightarrow 3,6$ were calculated to $0.23: 0.15: 1.00: 0.15: 0.11: 0.12$. The presence of mixed glycosidic linkages such as $1 \rightarrow 4,1 \rightarrow 3$ and $1 \rightarrow 6$ in the $F 1$ backbone assumed that it had stair-like structural features as depicted in Figure 5. The glycosidic linkages of $\mathrm{F} 1$ were also inferred from ${ }^{1} \mathrm{H}-$ and ${ }^{13} \mathrm{C}-\mathrm{NMR}$ spectra (Table 3, Figure 5). Based on the available data in the literature [30], the resonance from the ${ }^{1} \mathrm{H}-\mathrm{NMR}$ spectrum at $5.52 \mathrm{ppm}$ was attributed to a proton from anomeric carbons in the $\alpha$ configuration. The appearance of the anomeric carbon signals at 100.2 and $100.0 \mathrm{ppm}$ also indicated that the $(1 \rightarrow 4)$-D-Glcp and $(1 \rightarrow 3)$-D-Glcp were both in the $\alpha$-anomeric configuration, suggesting the residue appeared to be an $\alpha$-glucan (Table 3). The carbon signal at $75.3 \mathrm{ppm}$ should be $\mathrm{C}-4$ of the $(1 \rightarrow 4)$-D-Glcp, which was shifted about $6 \mathrm{ppm}$ downfield compared with the resonance of standard glycoside due to the effect of the glycosylation [31]. On the other hand, the C-3 signal at $77.7 \mathrm{ppm}$ of the $(1 \rightarrow 3)$-D-Glcp appeared to be at 5 ppm downfield compared with that of C-3 of standard glycoside. The carbon signals at 73.7, 71.9, 71.7 and $61.0 \mathrm{ppm}$ corresponded to C-3, C-2, C-5 and C-6 of the $(1 \rightarrow 4)-\alpha-D-G l c p$, respectively. The other signals at 73.1, 72.1, 70.0 and $61.3 \mathrm{ppm}$ corresponded to C-5, C-2, C-4 and C- 6 of the $(1 \rightarrow 3)-\alpha-D-G l c p$, respectively. Furthermore, another anomeric proton at $4.68 \mathrm{ppm}$ was observed with a chemical shift of $\mathrm{C}-1$ at $103.3 \mathrm{ppm}$, indicating the $\beta$-configuration of glucose residue. The carbon signal at $69.3 \mathrm{ppm}$ should be C-6 of the $(1 \rightarrow 6)-\mathrm{D}-\mathrm{Glcp}$, which was shifted about $8 \mathrm{ppm}$ downfield compared with the resonance of the standard glycoside. This was confirmed from the inverted signal of the DEPT spectrum [Figure 5(c)]. The signals at 76.3, 76.1, 74.0 and 70.0 ppm corresponded to C-5, C-3, C-2, C-4 of the $(1 \rightarrow 6)-\beta$-D-Glcp. In addition, the carbon signals of 76.6, 76.0, 73.8, 70.0 and 60.9 ppm were assigned to C-5, C-3, C-2, C-4 and C-6 of $(1 \rightarrow)-\beta-\mathrm{D}-\mathrm{Glcp}$, which suggested as a terminal glucose residue. These were in good agreement with the GC/MS data. However, the other glycosidic linkages suggested in the GC/MS data, such as $1 \rightarrow 3,6$ and $1 \rightarrow 4,6$ 
(branching points) were not able to be determined at the NMR spectrum due to complex and overlaid peaks.

Table 3. ${ }^{1} \mathrm{H}$ - and ${ }^{13} \mathrm{C}$-NMR spectral data of $\mathrm{F} 1$ and $\mathrm{F} 2$ in $\mathrm{D}_{2} \mathrm{O} \cdot{ }^{1} \mathrm{H}$ and ${ }^{13} \mathrm{C}$ chemical shifts (relative to external TSP,$=0 \mathrm{ppm}$ ) for $\mathrm{F} 1$ and $\mathrm{F} 2$ in aqueous solution.

\begin{tabular}{|c|c|c|c|c|c|c|c|}
\hline Sample & Residue & C-1/H-1 & C-2/H-2 & C-3/H-3 & C-4/H-4 & C-5/H-5 & C-6/H-6a, H-6b \\
\hline \multirow{4}{*}{ F1 } & $\underset{\alpha(1 \rightarrow 4) \text { Glu }}{\text { A }}$ & $100.2 / 5.52$ & $71.9 / 3.81$ & $73.7 / 4.13$ & $75.3 / 3.77$ & $71.7 / 3.99$ & $61.0 / 3.89,4.05$ \\
\hline & $\frac{\text { B }}{\alpha(1 \rightarrow 3) \text { Glu }}$ & $100.0 / 5.51$ & $72.1 / 3.72$ & $77.7 / 3.81$ & $70.0 / 3.60$ & $73.1 / 3.90$ & $61.3 / 3.88,4.00$ \\
\hline & $\begin{array}{c}\text { C } \\
\beta(1 \rightarrow 6) \text { Glu }\end{array}$ & $103.1 / 4.68$ & $74.0 / 3.47$ & $76.1 / 3.71$ & $70.0 / 3.58$ & $76.3 / 3.52$ & $69.3 / 4.01,4.37$ \\
\hline & $\begin{array}{c}\mathrm{D} \\
\beta(1 \rightarrow) \mathrm{Glu}\end{array}$ & $103.3 / 4.68$ & $73.8 / 3.49$ & $76.0 / 3.67$ & $70.0 / 3.58$ & $76.6 / 3.45$ & $60.9 / 3.51,3.85$ \\
\hline \multirow{4}{*}{$\mathrm{F} 2$} & $\begin{array}{c}\mathrm{A} \\
\alpha(1 \rightarrow 4) \mathrm{Glu}\end{array}$ & $100.2 / 5.53$ & $71.9 / 3.80$ & $73.7 / 4.12$ & $76.1 / 3.75$ & $71.6 / 3.99$ & $61.0 / 3.89,4.05$ \\
\hline & $\frac{\mathrm{B}}{\alpha(1 \rightarrow 3) \mathrm{Glu}}$ & $100.0 / 5.52$ & $72.4 / 3.73$ & $77.5 / 3.80$ & $70.2 / 3.60$ & $73.5 / 3.90$ & $61.3 / 3.88,4.00$ \\
\hline & $\begin{array}{c}\text { C } \\
\beta(1 \rightarrow 6) \mathrm{Glu}\end{array}$ & $103.1 / 4.68$ & $74.0 / 3.55$ & $76.1 / 3.69$ & $70.0 / 3.58$ & $76.3 / 3.52$ & $69.3 / 4.01,4.37$ \\
\hline & $\begin{array}{c}\text { D } \\
\beta(1 \rightarrow) \text { Glu } \\
\end{array}$ & $103.3 / 4.67$ & $73.9 / 3.49$ & $76.3 / 3.67$ & $70.0 / 3.58$ & $76.5 / 3.5$ & $60.9 / 3.51,3.85$ \\
\hline
\end{tabular}

Figure 5. (A) ${ }^{1} \mathrm{H}-\mathrm{NMR}$ spectrum $\left(600 \mathrm{MHz}, \mathrm{D}_{2} \mathrm{O}, 50{ }^{\circ} \mathrm{C}\right) ;($ B $){ }^{13} \mathrm{C}-\mathrm{NMR}$ spectrum $\left(150 \mathrm{MHz}, \mathrm{D}_{2} \mathrm{O}, 50{ }^{\circ} \mathrm{C}\right)$; (C) DEPT- $135-{ }^{13} \mathrm{C}\left(150 \mathrm{MHz}, \mathrm{D}_{2} \mathrm{O}, 50{ }^{\circ} \mathrm{C}\right)$; and (D) HMQC spectrum $\left(600 \mathrm{MHz}, \mathrm{D}_{2} \mathrm{O}, 50{ }^{\circ} \mathrm{C}\right)$ of $\mathrm{F} 1$ in aqueous solution.
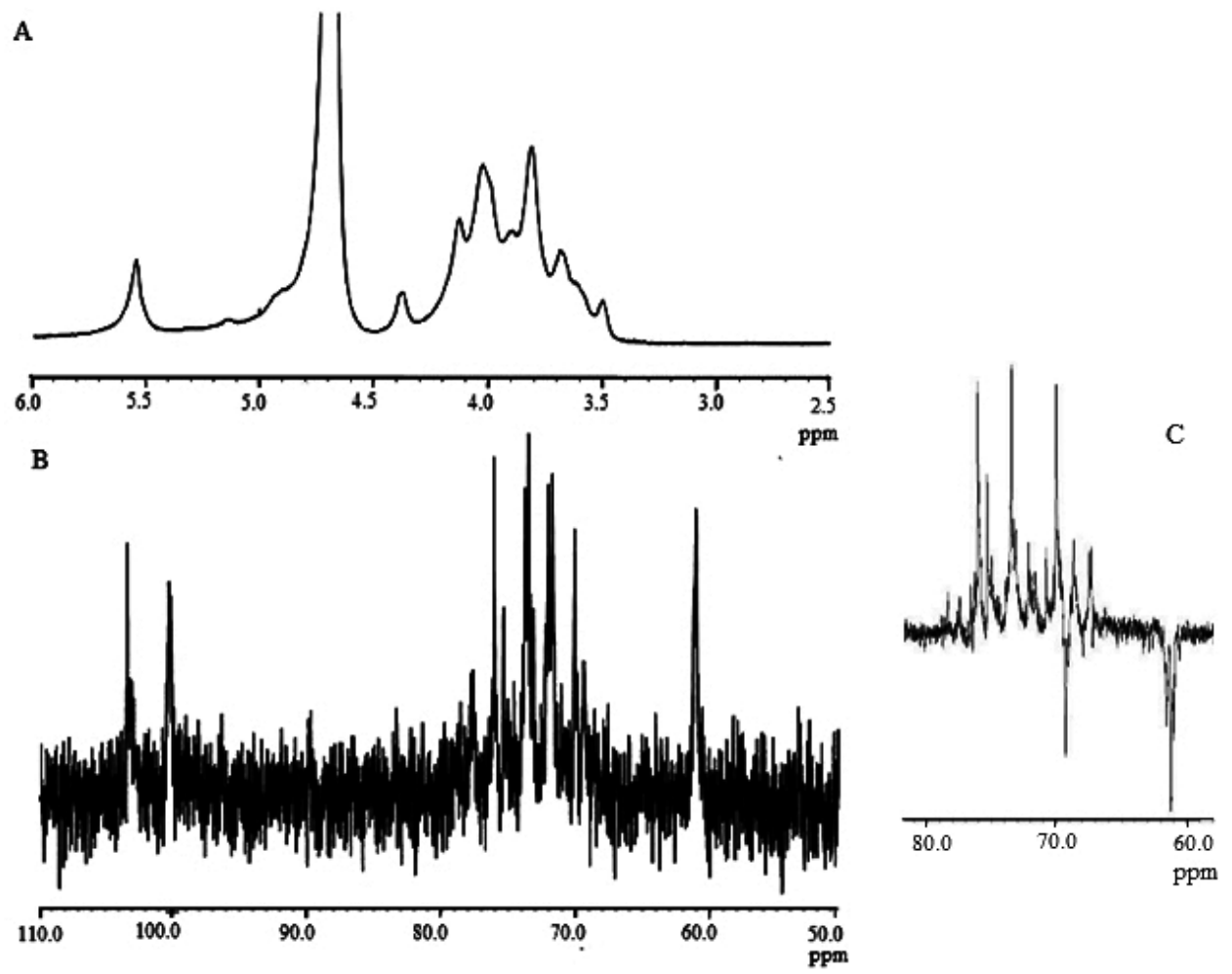
Figure 5. Cont.

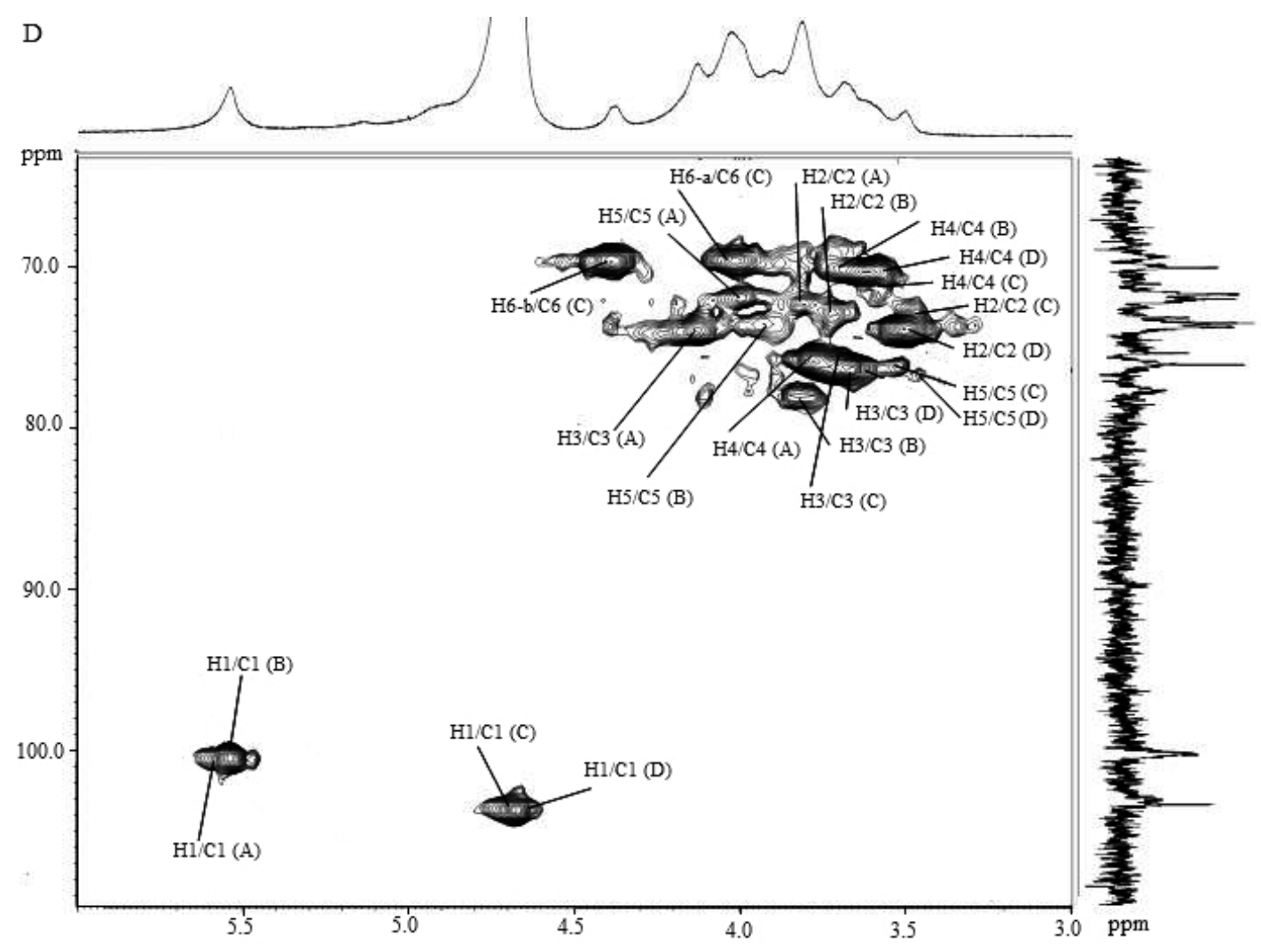

It was shown in Table 2 that the major component of the derivatives from F2 was 2,4,6-Me $-\mathrm{Glc} p$, indicating that the backbone of F2 might be mainly connected with 1,3-glycosidic linkages. In addition, F2 included considerable amounts of 2,3,6-Me $-\mathrm{Glc} p$ and 2,3,4-Me $-\mathrm{Glc} p$, indicating the presence of 1,4 and 1,6-glycosidic linkages in the backbone. The mixed glycosidic linkages $(1 \rightarrow 4,1 \rightarrow 3$ and $1 \rightarrow 6)$ in F2 implied that it also had stair-like structural features. The ratios of the glycosidic linkages of $1 \rightarrow$, $1 \rightarrow 4,1 \rightarrow 3,1 \rightarrow 6,1 \rightarrow 4,6,1 \rightarrow 3,6$ were calculated to $0.73: 0.65: 1.00: 0.35: 0.10: 0.60$. This result indicated that the glycosidic linkages of the F2 backbone were more heterogeneous than those of the F2 backbone, suggesting that the backbone structures of the two were significantly different. The resonances from the ${ }^{1} \mathrm{H}-\mathrm{NMR}$ spectrum at 5.52 and $5.53 \mathrm{ppm}$ were attributed to protons from anomeric carbons at the $\alpha$ configuration. The appearance of the anomeric carbon signals at 100.2 and $100.0 \mathrm{ppm}$ indicated that the $(1 \rightarrow 4)-\mathrm{D}-\mathrm{Glc} p$ and $(1 \rightarrow 3)$-D-Glc $p$ were both at the $\alpha$-anomeric configuration (Table 3). The carbon signals at 76.1, 73.7, 71.9, 71.6 and 61.0 ppm corresponded to C-4, C-3, C-2, C-5 and C-6 of the $(1 \rightarrow 4)-\alpha-D-G l c p$, respectively. The signals at 77.5, 73.5, 72.4, 70.2 and $61.3 \mathrm{ppm}$ corresponded to C-3, C-5, C-2, C-4 and C-6 of the $(1 \rightarrow 3)-\alpha-D-G l c p$, respectively. Another anomeric proton at $4.68 \mathrm{ppm}$ was observed with the chemical shift of $\mathrm{C}-1$ at $103.1 \mathrm{ppm}$, indicating the $\beta$-configuration of glucose residue. In addition, the carbon signal at $69.3 \mathrm{ppm}$ should be C-6 of the $(1 \rightarrow 6)$-D-Glc $p$ by the downfield shift of $8 \mathrm{ppm}$, which was also confirmed by the DEPT spectrum. The signals at 76.3, 76.1, 74.0 and $70.0 \mathrm{ppm}$ corresponded to C-5, C-3, C-2, C-4 of the $(1 \rightarrow 6)-\beta-\mathrm{D}-\mathrm{Glc} p$. The carbon signals of 76.5, 76.3, 73.9, 70.0 and 60.9 ppm were assigned to C-5, C-3, C-2, C-4 and C-6 of $(1 \rightarrow)-\beta$-D-Glc $p$, suggesting as a terminal glucose residue. It was also difficult to determine the other glycosidic linkages $(1 \rightarrow 3,6$ and $1 \rightarrow 4,6)$ suggested in GC/MS data at the NMR spectrum due to the 
complexity of the peaks. According to Maeda and Chihara [32], the $\beta$ - $(1 \rightarrow 3)$ and $(1 \rightarrow 6)$ glycosidic linkages of the polysaccharides from Lentinula edodes was a major factor for its strong anticancer activity. However, in the current study, the most active proteoglycans, F1 and F2, had considerably different glycosidic linkages, suggesting that the type of glycosidic linkages might not be a major factor affecting their biological activity.

\section{Experimental}

\subsection{Materials}

The dried and milled fruiting body of Hypsizygus marmoreus was kindly provided by HaeSong Bio Co. (Gangneung, Korea) and stored at $-20^{\circ} \mathrm{C}$ prior to the extraction of proteoglycans.

\subsection{Preparation of the Alkali and Acid Extractable Proteoglycans}

Figure 6 shows the extraction procedure of the water-unextractable proteoglycans from H. marmoreus. The milled sample was refluxed with $80 \%$ ethanol $(\mathrm{EtOH})$ at $60{ }^{\circ} \mathrm{C}$ for $2 \mathrm{~h}$ to remove the lipophilic substances and was then heated in boiling water for $2 \mathrm{~h}(\times 3)$.

Figure 6. The extraction scheme used to isolate water-unextractable proteoglycans from Hypsizygus marmoreus.

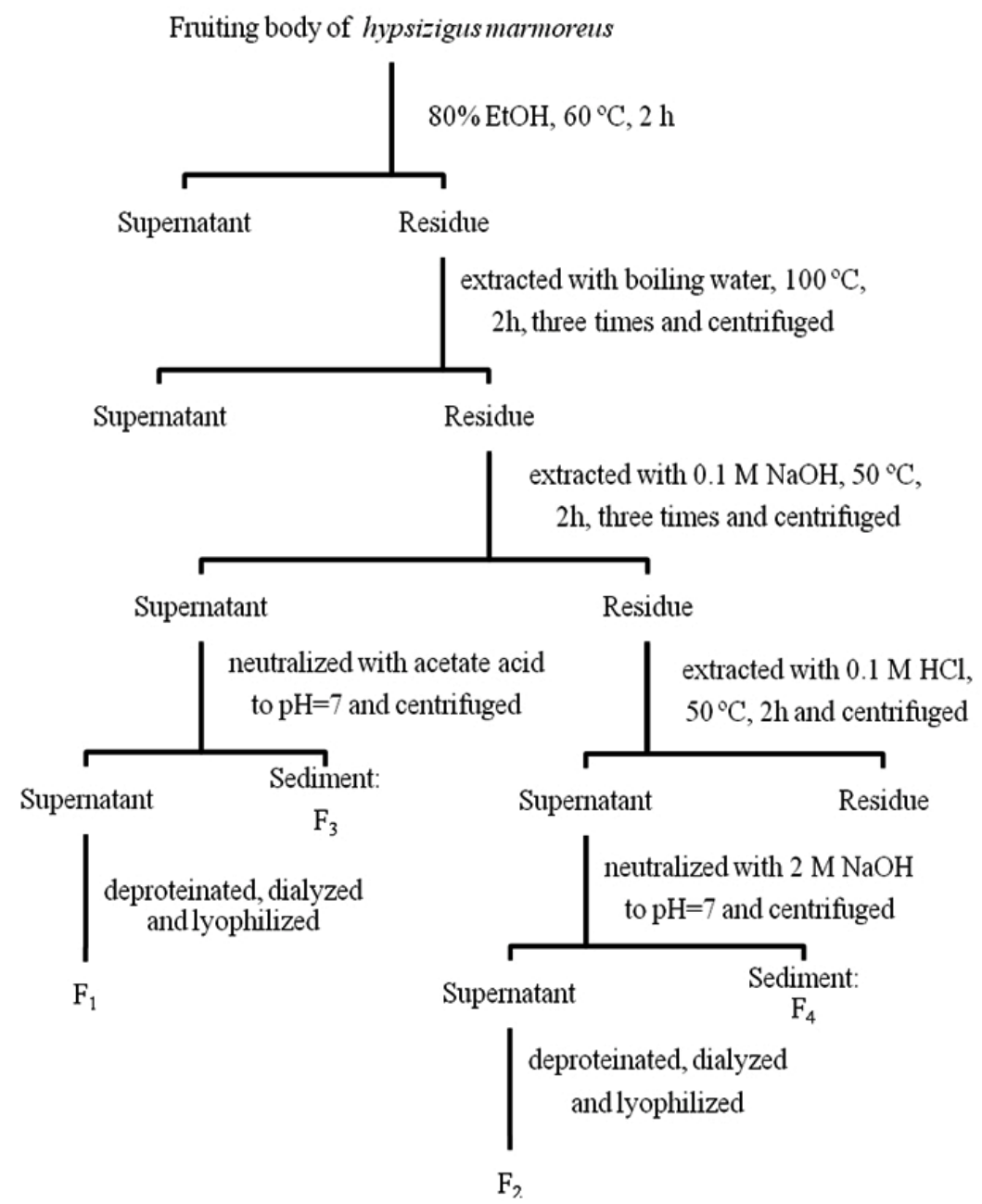


After centrifugation at $1,500 \mathrm{~g}$ for $10 \mathrm{~min}$, the supernatant was discarded to remove the water soluble polysaccharides, and the remaining residue was dried in a vacuum oven at $25{ }^{\circ} \mathrm{C}$. The dried biomass $(10 \mathrm{~g})$ was extracted with $0.1 \mathrm{M} \mathrm{NaOH}(500 \mathrm{~mL})$ at $50{ }^{\circ} \mathrm{C}$ for $2 \mathrm{~h}(\times 2)$, followed by the centrifugation at $1,500 \mathrm{~g}$ for $10 \mathrm{~min}$. The supernatants were collected and neutralized by acetic acid. After incubating the supernatants at $4{ }^{\circ} \mathrm{C}$ over night, the sediment was separated by centrifugation (3,000 $\mathrm{g}$ for $20 \mathrm{~min})$ to obtain alkali-insoluble proteoglycan (F3). EtOH was added to the supernatants to get a final $\mathrm{EtOH}$ concentration of $70 \%(\mathrm{v} / \mathrm{v})$, and then the solution was placed at $4{ }^{\circ} \mathrm{C}$ overnight. The precipitate was obtained by centrifugation at 1,500 $\mathrm{g}$ for $10 \mathrm{~min}$ and dried in a vacuum oven at $25^{\circ} \mathrm{C}$. The dried residue was redissolved in distilled water, deproteinated by the Sevag method [33], exhaustively dialyzed against distilled water and then freeze-dried to yield the alkali-soluble proteoglycan (F1). The alkali extracted residue was further extracted with $0.1 \mathrm{M} \mathrm{HCl}$ at $50{ }^{\circ} \mathrm{C}$ for $2 \mathrm{~h}$, followed by centrifugation, neutralization and incubation at $4{ }^{\circ} \mathrm{C}$ overnight. This sediment produced the acid-insoluble portion of the proteoglycan (F4). The proteoglycans in the supernatant were precipitated using EtOH (70\%), deproteinated by the Sevag method, dialyzed and lyophilized to yield the acid soluble proteoglycan (F2) fraction.

\subsection{Determination of the Total Carbohydrate, Protein and Monosaccharide Composition of} the Proteoglycans

The total carbohydrate and protein content of the proteoglycans were determined by the phenol-sulfuric acid method using glucose as a standard [34], and by the Lowry method [35] using a commercial assay kit (Bio-Rad, Hercules, CA, USA), respectively. The monosaccharide composition was quantitatively determined after total hydrolysis of proteoglycans (60 $\mathrm{mg}$ ) using $2 \mathrm{M}$ trifluoroacetic acid (TFA) at $120{ }^{\circ} \mathrm{C}$ for $5 \mathrm{~h}$. Hydrolysate was neutralized by $2 \mathrm{M} \mathrm{NaOH}$ (final $\mathrm{pH} 5-8$ ), evaporated with dried nitrogen stream and dissolved in $100 \mu \mathrm{L}$ of distilled water. Sample injected into the HPLC system (eluting with $85 \%$ acetonitrile) consisting of a pump (Waters 510, Milford, MA, USA), an injection valve (Rheodyne 7010, Rohnert Park, CA, USA) with a $20-\mu \mathrm{L}$ sample loop, a column (carbohydrate analysis column, $4.6 \times 250 \mathrm{~mm}$, Waters) and a refractive index (RI) detector (Waters 2414).

\subsection{Glycosidic Linkage Analysis}

The glycosidic linkage analysis of the polysaccharide moiety of the F1 and F2 fractions was carried out using the method of Hakomori [29] with slight modifications. The proteoglycans (2-3 mg) were dissolved in DMSO $(0.5 \mathrm{~mL})$ under nitrogen and then methylated with $\mathrm{CH}_{3} \mathrm{I}(0.3 \mathrm{~mL})$ and dried $\mathrm{NaOH}$ powder $(20 \mathrm{mg})$. Partially methylated alditol acetates were prepared from fully methylated samples by acid hydrolysis with $4 \mathrm{M} \mathrm{TFA}$ at $100{ }^{\circ} \mathrm{C}$ for $6 \mathrm{~h}$ followed by the reduction of the hydrolysates in water using $\mathrm{NaBD}_{4}$ and acetylation with acetic anhydride. The partially-methylated alditol acetates were analyzed by gas chromatography-mass spectrometry (GC-MS) (6890N/MSD 5973, Agilent Technologies, Santa Clara, CA, USA) using a HP-5MS capillary column $(30 \mathrm{~m} \times 0.25 \mathrm{~mm} \times 0.25 \mu \mathrm{m})$ (Agilent Technologies) under previously reported conditions [36]. 


\subsection{Nuclear Magnetic Resonance (NMR) Spectroscopy}

For structural assignments, the spectra on the F1 and F2 fractions were recorded on a solution of $10 \mathrm{mg}$ in $0.5 \mathrm{~mL} \mathrm{D} \mathrm{D}_{2} \mathrm{O}$ at $50{ }^{\circ} \mathrm{C} .{ }^{1} \mathrm{H}-,{ }^{13} \mathrm{C}$ - and DEPT- $135-{ }^{13} \mathrm{C}-\mathrm{NMR}$ spectra were recorded on a JEOL ECA-600 spectrometer (JEOL, Akishima, Japan), equipped with a $5 \mathrm{~mm}$ multi-nuclear auto-turning $\mathrm{TH}$ tunable probe, at a base frequency of $150 \mathrm{MHz}$ for ${ }^{13} \mathrm{C}$ and $600 \mathrm{MHz}$ for ${ }^{1} \mathrm{H}$, respectively. Two-dimensional ${ }^{1} \mathrm{H}-{ }^{1} \mathrm{H}$ COSY, TOCSY, and ${ }^{1} \mathrm{H}-{ }^{13} \mathrm{C}$ HMQC, HMBC experiments were conducted using the pulse programs supplied with the manual.

\subsection{Determination of the Weight Average Molecular Weight}

The weight average molecular weight $\left(\mathrm{M}_{\mathrm{w}}\right)$ and radius of gyration $\left(\mathrm{R}_{\mathrm{g}}\right)$ of the proteoglycans were determined using our previously reported method [15]. Briefly, the F1 and F2 proteoglycans were dissolved in distilled water, and the F3 and F4 proteoglycans were dissolved in $0.01 \mathrm{~N} \mathrm{NaOH}(1 \mathrm{~mL})$, heated at $50{ }^{\circ} \mathrm{C}$ for $15 \mathrm{~min}$, diluted with water $(1 \mathrm{~mL})$ and neutralized with $0.01 \mathrm{M} \mathrm{HCl}$. The proteoglycan solution was heated in a microwave oven (RE-552W, SamSung, Seoul, Korea) for $30 \mathrm{~s}$ prior to analysis using high-performance size-exclusion chromatography (HPSEC) coupled with an UV (\#2484, Waters, Milford, MA, USA), multi-angle laser light-scattering (MALLS) (Heleos, Wyatt Technology Corp., Santa Barbara, CA, USA) and refractive index (RI) (\#2414, Waters) detection system (HPSEC-UV-MALLS-RI system) using a SEC column (TSK G5000 PW, $7.5 \times 600$ mm, TosoBiosep, Montgomeryville, PA, USA). The $\mathrm{M}_{\mathrm{w}}$ and $\mathrm{R}_{\mathrm{g}}$ values were calculated from the data collected from the MALLS and RI detectors using ASTRA 5.3 software (Wyatt Technology Corp.).

\subsection{Assays for Macrophage Proliferation}

The impact of the proteoglycans on macrophage proliferation was determined using Raw264.7 cells (ATCC, Rockville, MD, USA), following our previously described method [15]. Briefly, the cells in RPMI-1640 medium containing 10\% Fetal Bovine Serum (FBS) were incubated with the sample solution at $1.5,3,6$, or $12 \mu \mathrm{g} / \mathrm{mL}$ in a 96 -well microplate. Control wells were treated with the medium only. Proliferation was quantified by the WST-1 assay described above.

\subsection{Nitric Oxide Production}

The effect of proteoglycans on nitric oxide (NO) release was determined by measuring the NO levels in the culture supernatant using the Griess reaction as described by Green et al. [37]. Raw264.7 cells $\left(1 \times 10^{6}\right.$ cells $\left./ \mathrm{mL}\right)$ were incubated in an RPMI-1640 medium containing $10 \% \mathrm{FBS}$ for $24 \mathrm{~h}$ at $37{ }^{\circ} \mathrm{C}$ in the presence of $5 \% \mathrm{CO}_{2}$. The sample solution at $1.5,3,6$, or $12 \mu \mathrm{g} / \mathrm{mL}$, or lipopolysaccharide (LPS, $1 \mu \mathrm{g} / \mathrm{mL}$ ), which was used as a positive control, were added to the cultured cells in triplicate, and the cells were incubated for $24 \mathrm{~h}$ at $37{ }^{\circ} \mathrm{C}$. After treating with Griess reagent $(1 \%$ [w/v] sulfanilamide and $0.1 \%[\mathrm{w} / \mathrm{v}] N$-[1-naphthyl] ethylenediamine hydrochloride in $2.5 \%[\mathrm{v} / \mathrm{v}]$ phosphoric acid), the absorbance of the solution was measured at $540 \mathrm{~nm}$ with an EL-800 microplate reader (BioTek instruments). NO production from the Raw264.7 cells was calculated with reference to a standard curve that was obtained with $\mathrm{NaNO}_{2}(1-200 \mu \mathrm{M}$ in the culture medium). 


\subsection{Assay for Cytokine Secretion}

The concentration of prostaglandin $\mathrm{E}_{2}\left(\mathrm{PGE}_{2}\right)$ and interleukin-1 $\beta$ (IL-1 $\left.\beta\right)$ released from the Raw264.7 cell line after treatment with the proteoglycans was determined using an ELISA assay (Prostaglandin $\mathrm{E}_{2}$, EIA Kit, Assay Designs, Ann Arbor, MI, USA; Quantikine Immunoassay Mouse IL-1 $\beta$, R\&D Systems, Minneapolis, USA). Raw264.7 cells $\left(1 \mathrm{~mL}, 1 \times 10^{6}\right.$ cells $\left./ \mathrm{mL}\right)$ were incubated in RPMI-1640 medium containing $10 \%$ FBS with the sample solution at $1.5,3,6$ or $12 \mu \mathrm{g} / \mathrm{mL}$ in a 24 -well microplate. LPS $(1 \mu \mathrm{g} / \mathrm{mL})$ was used as a positive control. After incubation for $72 \mathrm{~h}$, the amount of $\mathrm{PGE}_{2}$ and IL-1 $\beta$ in the supernatants was detected and quantified according to the manufacturer's protocol.

\subsection{Reverse Transcription-Polymerase Chain Reaction (RT-PCR)}

Raw264.7 cells $\left(1 \times 10^{6}\right.$ cells/well $)$ were incubated at $37{ }^{\circ} \mathrm{C}\left(5 \% \mathrm{CO}_{2}\right)$ with LPS $(1 \mu \mathrm{g} / \mathrm{mL})$ and $12 \mu \mathrm{g} / \mathrm{mL}$ of the proteoglycans for $18 \mathrm{~h}$. After incubation, total RNA was extracted from the cells using TRIzol Reagent (Invitrogen, Carlsbad, CA, USA), according to the manufacturer's protocol, and stored at $-80{ }^{\circ} \mathrm{C}$ until use. The extracted RNA $(2 \mu \mathrm{g})$ was quantified spectrophotometrically and used as templates for first strand cDNA synthesis with an oligo-(dT) 20 primer and Superscript III Reverse Transcriptase (Invitrogen). The resulting cDNA was amplified Polymerase Chain Reaction (PCR) using GoTaq Flexi DNA Polymerase (Promega, Madison, WI, USA). Cytokine sequence amplification was conducted using several primer sequence pairs: 5'-CCCTTCCGAAGTTTCTGGCAGCAGC-3' (forward) and 5'-GGCTGTCAGAGCCTCGTGGCTTTGG-3' (reverse) for iNOS (GenBank accession no. NM_010927.1), 5'-CCCCCACAGTCAAAGACACT-3' (forward) and 5'-GAGTCCATGTTCC AGGAGGA-3' (reverse) for COX-2 (GenBank accession no. NM_011198.3), 5'-ATGAGCACAG AAAGCATGATC-3' (forward) and 5'-TACAGGCTTGTCACTCGAATT-3' (reverse) for TNF- $\alpha$ (GenBank accession no. NM_013693.1), 5'-ATGGCAACTGTTCCTGAACTCAACT-3' (forward) and 5'-CAGGACAGGTATAGATTCTTTCCTTT-3' (reverse) for IL-1 $\beta$ (GenBank accession no. NM_008361.3), 5'-TTCCTCTCTGCAAGAGACT-3' (forward) and 5'-TGTATCTCTCTGAAGGA CT-3' (reverse) for IL-6 (GenBank accession no. NM_031168.1), and 5'-TGGAATCCTGTGGC ATCCATGAAAC-3' (forward) and 5'-TAAAACGCAGCTCAGTAACAGTCCG-3' (reverse) for $\beta$-actin (GenBank accession no. NM_007393.3). The PCR reactions were performed as follows: initial denaturation at $94{ }^{\circ} \mathrm{C}$ for $3 \mathrm{~min}$; 30 cycles of denaturation $\left(94{ }^{\circ} \mathrm{C}\right.$ for $\left.30 \mathrm{~s}\right)$, annealing $\left(56{ }^{\circ} \mathrm{C}\right.$ for $\left.40 \mathrm{~s}\right)$ and extension $\left(72{ }^{\circ} \mathrm{C}\right.$ for $1 \mathrm{~min}$ ); and the final extension step at $72{ }^{\circ} \mathrm{C}$ for $10 \mathrm{~min}$. PCR products were electrophoresed on $1 \%$ agarose gels and visualized by ethidium bromide staining. Gels were scanned and analyzed with image analysis software (Kodak Digital Science, Kennesaw, GA, USA), and the results were expressed with relative intensity compared to $\beta$-actin.

\subsection{Statistical Analyses}

All experiments were run in triplicate and the data are presented as the mean value with standard deviation. Statistical differences were tested using Student's $t$ test, a one-way analysis of variance (ANOVA), and Duncan's multiple-range test using Statistical Analysis System (SAS Institute, Cary, $\mathrm{NC}, \mathrm{USA})$. 


\section{Conclusions}

Alkali and acid extraction procedures led to the production of four water-unextractable proteoglycans (F1, F2, F3 and F4) from H. marmoreus, having various chemical compositions and $\mathrm{M}_{\mathrm{w}}$ values, as well as different molecular conformations. F1 and F2 fractions exhibited significant potency to induce NO and cytokine release from Raw264.7 cells, suggesting strong immunomodulating activities. The search for bioactive compounds that can boost the immune function is an important research area of immunopharmacological studies. The current study, therefore, demonstrates the potential for water-unextractable proteoglycans as medicinal, pharmacological and functional food ingredients.

\section{Acknowledgment}

This research was supported by the Basic Science Research Program (KRF-2008-F00159) of the National Research Foundation of Korea (NRF), funded by the Ministry of Education, Science and Technology.

\section{References and Notes}

1. Sasaki, T.; Takasuka, N. Further study of the structure of lentinan, an anti-tumor polysaccharide from Lentinus edodes. Carbohydr. Res. 1976, 47, 99-104.

2. Komatsu, N.; Okubo, S.; Kikumoto, S.; Kimura, K.; Saito, G.; Sasaki, S. Host mediated antitumor action of schizophyllan, a glucan produced by Schizophyllum commune. Gann 1971, 60, 557-563.

3. Tsugagoshi, S.; Ohash, F. Protein-bound polysaccharides preparation, PS-K. Protein-bound polysaccharide preparation, PS-K, effective against mouse sarcoma-180 and rat ascites hepatoma AH-13 by oral use. Gann 1974, 65, 557-565.

4. Wang, H.X.; Liu, W.K.; Ng, T.B.; Ooi, V.E.C.; Chang, S.T. Immunomodulatory and antitumor activities of a polysaccharide-peptide complex from a mycelial culture of Tricholoma sp., a local edible mushroom. Life Sci. 1995, 57, 269-281.

5. Lavi, I.; Friesem, D.; Geresh, S.; Hadar, Y.; Schwartz, B. An aqueous polysaccharide extract from the edible mushroom Pleurotus ostreatus induces anti proliferative and pro-apoptotic effects on HT-29 colon cancer cells. Cancer Lett. 2006, 244, 61-70.

6. Wong, S.M.; Wong, K.K.; Chiu, L.C.M.; Cheung, C.K. Non-starch polysaccharides form different developmental stages of Pleurotus tuber-regium inhibited the growth of human acute promyelocytic leukemia HL-60 cells by cell-cycle arrest an/or apoptotic induction. Carbohydr. Polym. 2007, 68, 206-217.

7. Surenjav, U.; Zhang, L.; Xu, X.; Zhagn, X.; Zeng, F. Effects of molecular structure on antitumor activities of $(1 \rightarrow 3)-\beta$-D-glucans from different Lentinus Edodes. Carbohydr. Polym. 2006, 63, 97-104.

8. Demleitner, S.; Kraus, J.; Franz, G. Synthesis and antitumor activity of sulfoalkyl derivatives of curdlan and lichenan. Carbohydr. Res. 1992, 226, 247-252.

9. Mizuno, T. The extraction and development of antitumor active polysaccharides from medicinal mushrooms in Japan. Int. J. Med. Mushrooms 1999, 1, 9-30. 
10. Peng, Y.; Zhang, L.; Zeng, F.; Kennedy, J. Structure and antitumor activities of the water-soluble polysaccharides from Ganoderma tsugae mycelium. Carbohydr. Polym. 2005, 59, 385-392.

11. Maeda, Y.Y.; Watanabe, S.T.; Chihara, C.; Rokunada, M. Denaturation and renaturation of $\beta-1,6$; 1,3-glucan, Lentinan, for the expression of T-cell mediated responses. Cancer Res. 1988, 48, 671-675.

12. Mizuno, T.; Yeohlui, T.; Kinoshita, T.; Zhuang, C.; Ito, H.; Mayuzumi, Y. Antitumor activity and chemical modification of polysaccharides from niohshimeji mushroom, Tricholma giganteum. Biosci. Biotechnol. Biochem. 1996, 60, 30-33.

13. Mizuno, T.; Kato, N.; Totsuka, A.; Takenaka, K.; Shinakai, K.; Shimizu, M. Fractionation, structural features and antitumor activity of water-soluble polysaccahrides from "Reishi", the fruit body of Ganoderma lucidum. J. Agric. Chem. Soc. Jpn. 1984, 58, 871-880.

14. Mizuno, T.; Suuzki, E.; Maki, K.; Tamaki, H. Fractionation, chemical modification and antitumor activity of water-insoluble polysaccharides of the fruiting body of Ganoderma lucidum. J. Agric. Chem. Soc. Jpn. 1985, 59, 1143-1151.

15. Bao, H.H.; Choi, W.S.; You, S.G. Effect of sulfated modification on the molecular characteristics and biological activities of polysaccharides from Hypsizygus marmoreus. Biosci. Biotechnol. Biochem. 2010, 74, 1408-1414.

16. Hromadkova, Z.; Ebringerova, A.; Valachovic, P. Comparison of classical and ultrasound-assisted extraction of polysaccharides from Salvia officinalis L. Ultrason. Sonochem. 1999, 5, 163-168.

17. Lindsey, J.W. An alkali-soluble factor present in normal brain tissue inhibits antigen-specific lymphocyte proliferation. J. Neuroimmunol. 2000, 103, 76-83.

18. Zhang, M.; Zhang, L.; Wang, Y.; Cheung, P.C.K. Chain conformation of sulfated derivatives of $\beta$-glucan from sclerotia of Pleurotus tuber-regium. Carbohydr. Res. 2003, 338, 2863-2870.

19. Synytsya, A.; Mickova, K.; Synytsya, A.; Jablonsky, I.; Spevacek, J.; Erban, V.; Kovarikova, E.; Copikova, J. Glucans from fruit bodies of cultivated mushrooms Pleurotus ostreatus and Pleurotus eryngii: Structure and potential prebiotic activity. Carbohydr. Polym. 2009, 76, 548-556.

20. Olennikov, D.N.; Agafonova, S.V.; Borovskii, G.B.; Penzina, T.A.; Rokhin, A.V. Alkali-soluble polysaccharides of Laetiporus Sulphureus (Bull.: Fr.) Murr fruit bodies. Appl. Biochem. Microbiol. 2009, 45, 693-697.

21. You, S.G.; Lim, S.T. Molecular characterization of corn starch using an aqueous HPSEC-MALLS-RI system under various dissolution and analytical conditions. Cereal Chem. 2000, 77, 303-308.

22. Bandtlow, C.E.; Zimmermann, D.R. Proteoglycans in the developing brain: New conceptual insight for old proteins. Physiol. Rev. 2000, 80, 1267-1290.

23. Porcheray, F.; Viaud, S.; Rimaniol, A.C.; Leone, C.; Samah, B.; Dereuddre-Bosquet, N.; Dormont, D.; Gras, G. Macrophage activation switching: An asset for the resolution of inflammation. Clin. Exp. Immunol. 2005, 142, 481-489.

24. Jiao, L.; Li, X.; Li, T.; Jiang, P.; Zhang, L.; Wu, M.; Zhang, L. Characterization and anti-tumor activity of alkali-extracted polysaccharide from Enteromorpha intestinalis. Int. Immunopharmacol. 2009, 9, 324-329. 
25. Yadomae, T.; Ohno, N. Structure-activity relationship of immunomodulating (1,3)- $\beta$-D-glucans. Recent Res. Dev. Chem. Pharm. Sci. 1996, 1, 23-33.

26. You, S.G.; Yang, C.; Lee, H.Y.; Lee, B.Y. Molecular characteristics of partially hydrolyzed fucoidans from sporophyll of Undaria Pinnatifida and their in vitro anticancer activity. Food Chem. 2010, 119, 554-559.

27. Liu, C.; Xi, T.; Lin, Q.; Xing, Y.; Ye, L.; Luo, X.; Wang, F. Immunomodulatory activity of polysaccharides isolated from Strongylocentrotus nudus eggs. Int. Immunopharmacol. 2008, 8, 1835-1841.

28. Na, Y.S.; Kim, W.J.; Kim, S.M.; Park, F.K.; Lee, S.M.; Kim, S.O.; Synytsya, A.; Park, Y.I. Purification, characterization and immunostimulating activity of water-soluble polysaccharide isolated from Capsosiphon fulvescens. Int. Immunopharmacol. 2010, 10, 364-370.

29. Hakomori, S.I. A rapid permethylation of glycolipid, and polysaccharide catalyzed by methylsulfinyl carbanion in dimethyl sulfoxide. J. Biochem. 1964, 55, 205-208.

30. Cui, F.J.; Tao, W.Y.; Xu, Z.H.; Guo, W.J.; Xu, H.Y.; Ao, Z.H.; Jin, J.; Wei, Y.Q. Structural analysis of anti-tumor heteropolysaccharide GFPS1b from the cultured mycelia of Grifola frondosa GF9801. Bioresour. Technol. 2007, 98, 395-401.

31. Agrawal, P.K. NMR spectroscopy in the structural elucidation of oligosaccharides and glycosides. Phytochemistry 1992, 31, 3307-3330.

32. Maeda, Y.Y.; Chihara, G. Lentinan and other antitumoral polysaccharides. In Immunomodulatory Agents form Plants; Wagner, H., Ed.; Birkhauser Verlag: Basel, Switzerland, 1999; pp. 203-221,

33. Sevag, M.G.; Lackman, D.B.; Smolens, J. The isolation of the components of streptococcal nucleoproteins in serologically active form. J. Biol. Chem. 1938, 124, 425-436.

34. Dubois, M.; Gilles, K.A.; Hamilton, J.K.; Rebers, P.A.; Smith, F. Colorimetric method for determination of sugars and related substances. Anal. Chem. 1956, 28, 350-356.

35. Lowry, O.H.; Rosebrough, N.J.; Farr, A.L.; Randall, R.J. Protein measurement with the Folin-Phenol reagents. J. Biol. Chem. 1951, 193, 265-275.

36. Bao, H.; You, S.G. Molecular characteristics of water-soluble extracts from Hipsizigus marmoreus and their in vitro growth inhibition of various cancer cell lines and immunomodulatory function in Raw264.7 cells. Biosci. Biotechnol. Biochem. 2011, 75, 891-898.

37. Green, L.C.; Wanger, D.A.; Glogowski, J.; Skipper, P.L.; Wishnok, J.S.; Tannenbaum, S.R. Analysis of nitrate, nitrite, and $[15 \mathrm{~N}]$ nitrate in biological fluids. Anal. Biochem. 1982, 126, 131-136.

Sample Availability: Samples of the mushroom polysaccharides are available from the authors.

(C) 2012 by the authors; licensee MDPI, Basel, Switzerland. This article is an open access article distributed under the terms and conditions of the Creative Commons Attribution license (http://creativecommons.org/licenses/by/3.0/). 